\title{
Photosynthesis, Growth, and Yield Response of 'Casselman' Plum to Various Ozone Partial Pressures during Orchard Establishment
}

\author{
W.A. Retzlaff and L.E. Williams \\ Department of Viticulture and Enology, University of California-Davis, Kearney Agricultural \\ Center, Parker, CA 93648
}

T.M. DeJong

Department of Pomology, University of California, Davis, CA 95616

Additional index words. trunk cross-sectional area, nitrogen, leaf fall, fruit weight, fruit number, 'Citation' rootstock

\begin{abstract}
Nursery stock of plum (Prunus salicina Lindel., 'Casselman') was planted 1 Apr. 1988 in an experimental orchard at the Kearney Agricultural Center, Univ. of California, near Fresno. The trees were enclosed in open-top fumigation chambers on 1 May 1989 and exposed to three atmospheric ozone partial pressures (charcoal-filtered air, ambient air, and ambient air + ozone) from 8 May to 15 Nov. 1989 and from 9 Apr. to 9 Nov. 1990. Trees grown outside of chambers were used to assess chamber effects on tree performance. The mean 12-hour $(0800-2000$ HR Pacific Daylight Time) ozone partial pressures during the 2-year experimental period in the charcoal-filtered, ambient, ambient + ozone, and nonchamber treatments were $0.044,0.059,0.111$, and $0.064 \mu \mathrm{Pa}^{-1} \mathrm{~Pa}^{-1}$ in 1989 and 0.038 , $0.050,0.090$, and $0.050 \mathrm{pPa} \cdot \mathrm{Pa}^{-1}$ in 1990 , respectively. Leaf net $\mathrm{CO}_{2}$ assimilation rate of 'Casselman' plum decreased with increasing atmospheric ozone partial pressure from the charcoal-filtered to ambient + ozone treatment. There was no difference in plum leaf net $\mathrm{CO}_{2}$ assimilation rate between the ambient chamber and nonchamber plots. Trees in the ambient + ozone treatment had greater leaf fall earlier in the growing season than those of the other treatments. Cross-sectional area growth of the trunk decreased with increasing atmospheric ozone partial pressures from the charcoal-filtered to ambient + ozone treatment. Yield of plum trees in 1990 was $8.8,6.3,5.5$, and $5.5 \mathrm{~kg} /$ tree in the charcoal-filtered, ambient, ambient + ozone, and nonchamber treatments, respectively. Average fruit weight (grams/ fruit) was not affected by atmospheric ozone partial pressure. Fruit count per tree decreased as atmospheric ozone partial pressure increased from the charcoal-filtered to ambient + ozone treatment. Decreases in leaf gas exchange and loss of leaf surface area were probable contributors to decreases in trunk cross-sectional area growth and yield of young 'Casselman' plum trees during orchard establishment.
\end{abstract}

The planting of an orchard is a long-term investment, usually taking 3 or more years to bear a commercial crop, with continued economic production for another 15 to 30 years (LaRue and Johnson, 1989). The establishment and first few years' growth of newly planted trees are critical in determining overall orchard productivity once the trees are mature. It is during this time that the canopy and permanent limbs are established and the root system develops. Cultural practices have been developed to optimize growth during the establishment period (LaRue and Johnson, 1989). However, stress during this time could delay or disrupt orchard development, with long-term orchard productivity being less than optimum. For example, apple (Malus domestica Borkh. 'Cox's Orange Pippin' and 'Golden Delicious') trees were smaller and lower yielding as a result of competition for water and mineral nutrients during the first 3 years of growth in an orchard plot with a continuous grass cover compared to a clean-cultivated plot (Stinchcombe and Stott, 1983).

More than 2,000,000 $t$ of fruit and nut crops are produced in the San Joaquin Valley of California annually. However, this fruit production region is characterized by ambient ozone partial pressures that consistently exceed U.S. Environmental Protec-

Received for publication 26 Nov. 1991. Accepted for publication 4 May 1992. This study was funded in part by a grant from the California State Air Resources Board. The statements and conclusions of this report are those of the Univ. of California and not necessarily those of the California State Air Resources Board. The mention of commercial products, their source, or their use in connection reported herein is not to be construed as either an actual or implied endorsement of said products. The cost of publishing this paper was defrayed in part by the payment of page charges. Under postal regulations, this paper therefore must be hereby marked advertisement solely to indicate this fact. tion Agency standards of $0.12 \mu \mathrm{Pa} \cdot \mathrm{Pa}^{-1}$ at various times during the growing season (Cabrera et al., 1988). Ozone-induced reductions in photosynthesis previously have been related to reductions in crop growth and yield (Lehnherr et al., 1987; Reich and Amundson, 1985; Takemoto et al., 1988). Yield reductions in 'Valencia' orange [Citrus sinensis (L.) Osbeck] trees have been documented in ozone partial pressures $>0.020 \mu \mathrm{Pa} \cdot \mathrm{Pa}^{-1}$ (Olszyk et al., 1990). Ozone-induced yield reductions in other annual and perennial crops have been reported (Adaros et al., 1990; Brewer and Ashcroft, 1983; Mebrahtu et al., 1991).

Two recent studies have demonstrated that net photosynthesis and trunk circumference of various fruit and nut tree species and cultivars of the same species decreased with increasing atmospheric ozone partial pressure (Retzlaff et al., 1991, 1992). However, these studies were conducted on nursery stock trees (bud grafted the previous year) that had been transplanted directly into open-top chambers. The effects of ozone air pollution on deciduous fruit tree crops in a production orchard during and/or following the orchard establishment period are unknown. A long-term study examining the effects of ozone on growth and productivity of plum trees grown in the San Joaquin Valley of California was established in 1988. This report describes the effects of a range of atmospheric ozone partial pressures during the first 3 years of tree growth, a crucial period in which the canopy and permanent limbs are established, the root system develops, and the first yield is produced.

Abbreviations: A, ambient; $\mathrm{C}$, charcoal-filtered; $\mathrm{N}$, nonchamber; $\mathrm{Pn}$, net $\mathrm{CO}_{2}$ assimilation rate; $\mathrm{T}$, ambient + ozone. 


\section{Materials and Methods}

\section{Plant materials and ozone treatments}

Nursery stock of 'Casselman' plum on 'Citation' (Prunus hybrid) rootstock were planted 1 Apr. 1988 in an experimental orchard at the Kearney Agricultural Center, Univ. of California, near Fresno (lat. $36^{\circ} 36^{\prime} \mathrm{N}$, long. $119^{\circ} 30^{\prime} \mathrm{W}$ ). Tree and row spacing were 1.83 and $4.27 \mathrm{~m}$, respectively. Trees were trained to an open-vase shape, with other cultural practices being similar to those used for the commercial production of plums. Trees were irrigated at 17.5 liters/tree per week via low-volume fan jet sprinklers throughout the 1989 and 1990 growing seasons.

Open-top chamber frames used in this study were constructed from extruded aluminum tube-lock welded to $4-\mathrm{cm}$ thinwall tubing. The chamber dimensions were $3 \times 7 \times 3 \mathrm{~m}$ (width $\times$ length $\times$ height) on a $3 \times 7-\mathrm{m}$ rectangular base of $5 \times 30$ $\mathrm{cm}$ redwood boards. Chamber frames were put around the trees on 4 Nov. 1988. Each chamber contained four plum trees. The chamber air delivery system consisted of a blower located at one end of each chamber with four 23-cm-diameter plastic tube (Arizona Bag and Plastic Co., Phoenix) air ducts running from one end of the chamber to the other along the 7-m chamber length. Two of the air ducts ran along the sides of the chamber at a height of $1.5 \mathrm{~m}$ above the chamber floor. Air from these two ducts was directed toward the middle and top of the tree canopies within the chamber. An additional pair of air ducts was located directly beneath the trees, and this air was directed upward into the lower canopy. Air from all the ducts passed into the chamber atmosphere through $8.5-\mathrm{cm}$, diamond-shaped holes cut every $30 \mathrm{~cm}$ in the delivery tubes. This air delivery system provided air at a rate of $\approx 133 \mathrm{~m}^{3} \cdot \mathrm{min}^{-1}$ to each chamber, enough to change the air volume in the chambers about twice per minute. Clear, 0.3-mm polyvinylchloride (Goss Products, Corona, Calif.) walls were first put on the chambers 1-8 May 1989, and chamber blowers were turned on at that time. Chamber blowers were operated $24 \mathrm{~h}-\mathrm{day}^{-1}$ during the growing season.

Ozone treatments imposed in this study were charcoal-filtered air (C), ambient air (A), and ambient air + ozone (T). Treatments were randomly assigned to a chamber, and there were five replications containing one chamber of each treatment and an additional nonchamber $(\mathrm{N})$ plot. Ozone partial pressures in the treatment plots were monitored using a computer-controlled monitoring system described by Retzlaff et al. (1991). Ozone treatments were initiated on 8 May and continued until 15 Nov. 1989. After 15 Nov. 1989, the plastic chamber ends were removed. Plastic end walls were put back on the chambers before 10 Apr. 1990 and the ozone treatments re-initiated. All the plastic chamber walls were removed after 9 Nov. 1990.

Air for A was blown directly into the chamber. Air for C chambers was first drawn through activated charcoal filters before delivery into the chambers. Ozone for the T chambers was generated from dry ambient air with a Griffin (Lodi, N.J.) model GTC-2A ozone generator and delivered via teflon tubing to the delivery air stream of these chambers. The air was dried by a General Cable Corp. (Westminster, Colo.) Puregas heatless air drier (model F200A109-132). The ozone generator was computer-automated to increase or decrease the ozone output from 0800 to 2000 HR Pacific Daylight Time (PDT) depending on the ambient atmospheric ozone partial pressure. This system resulted in ozone partial pressures $\approx 1.8$ times ambient in the $\mathrm{T}$ chambers during the 2-year ozone exposure period.
Final ozone partial pressure data analysis was conducted by use of the means procedure (Proc Means) of the statistical analysis system (SAS Institute, 1985). Ozone 12-h means 0800-2000 HR PDT were calculated for each treatment. These ozone partial pressures were used to assess the effects of ozone air pollution on tree growth, development., and yield.

Oxides of nitrogen were measured continuously in the treatment/chambers with a Thermo Electron Corp. (Hillsborough, N.C.) model 14B Chemiluminescent NO-NO,-NO, gas analyzer to determine whether the Griffin ozone generation system was releasing oxides of nitrogen into the $\mathrm{T}$ chambers. No differences in the partial pressure of oxides of nitrogen were found among treatments during the 1989 or 1990 growing seasons (data not shown).

\section{Gas exchange}

Three weeks after treatment initiation in each year, leaf net $\mathrm{CO}_{2}$ assimilation was measured on all trees in the study plots. This process was repeated at 3-week intervals, and each tree was measured nine times in 1989 and 10 times in 1990. On each measurement day, leaf net $\mathrm{CO}_{2}$ assimilation (Pn) was measured on one leaf from each tree in every treatment (20 leaves/ treatment, 80 total leaves per sample day). Fully expanded leaves that had been in direct sunlight before data collection were selected for measurement. Measurements were made between 1000 and $1200 \mathrm{HR}$ PDT, and leaf temperatures and photon fluence rate averaged $30 \mathrm{C}$ and $1300 \mu \mathrm{mol} \cdot \mathrm{m}^{-2} \cdot \mathrm{s}^{-1}$, respectively, across all dates each year. Following measurement, the leaves were harvested from the tree and their leaf surface area determined with a LI-COR (Lincoln, Neb.) model LC3100 leaf area meter. Leaves were then dried in a forced-air oven at $70 \mathrm{C}$ until there was no further weight change and nitrogen concentration was later determined for each leaf using the Kjeldahl method.

All photosynthesis measurements were made by use of an Analytical Development Corp. (Hoddesdon, England) portable infrared gas analyzer (IRGA) (Model LCA-2), air supply unit with mass flowmeter (Model ASUM), data processor for the LCA-2 (Model DL-2), and broad leaf Parkinson leaf chamber. The IRGA was used in the differential mode. Air for the leaf chamber was taken from the open-top chambers in which the trees were growing or from ambient air for trees growing in the $\mathrm{N}$ plots.

\section{Growth measurements}

Circumference of each tree trunk was measured at monthly intervals from 1 May through 1 Dec. in 1989 and 1990. Painted bands on the trees $18 \mathrm{~cm}$ above the soil line were used as reference points to minimize measurement errors. The increase in trunk cross-sectional area from 1 May to 1 Dec. each year was calculated from the circumference measurements. Trees were visually inspected for foliar symptoms of chronic ozone injury when measurements were taken.

Leaf fall was measured by collecting the leaves from the ground below the trees in the chamber treatments $(\mathrm{C}, \mathrm{A}$, and T) at various times throughout both growing seasons. On 15 Dec. 1989 and 30 Nov. 1990, all leaves on the ground below the trees were collected, and any remaining foliage on the trees was stripped off to determine final foliage biomass. Collected leaves were dried and analyzed for nitrogen as stated previously.

Trees in the study were dormant-pruned on 7 Feb. 1989, 11 Jan. 1990, and 10 Jan. 1991. Fresh prunings were weighed and then placed in a forced-air oven at $70 \mathrm{C}$ until there was no further weight change, and final dry weight was determined. 


\section{Fruit yield}

Fruit from individual trees in each treatment was picked on 28 Aug. 1990. Individual tree fruit samples were passed through an Autoline (Reedley, Calif.) camera sizer/sorter and separated into six size classes. Number of fruit, fruit weight, and percent distribution in each size class were determined.

\section{Statistical analysis}

The main design was a randomized complete block with three ozone $(\mathrm{C}, \mathrm{A}$, and $\mathrm{T})$ treatments and five replications. The experiment was replicated/blocked five times to account for chamber location in the field and possible soil differences among chambers. Data for measurements that were repeated throughout the study were analyzed using a repeated measures analysis of variance (ANOVA) with two grouping factors (replication and treatment) and one within factor (time). Data collected on individual dates and/or only once during the study were analyzed by two-way ANOVA. In all analyses, linear contrasts with the 12-h mean ozone levels were used for a priori comparisons among treatment means $(\alpha<0.05)$. In addition, two-way ANOVA was used to compare the responses of trees in the ambient chambers with those of $\mathrm{N}$ plots. To remove subsampling variability from tests for treatment effects, the replication $\mathrm{x}$ treatment interaction was used to test treatment effects.

\section{Results}

\section{Ozone treatments}

Treatments were not imposed until the second year of growth, therefore no ozone data were collected in 1988. In 1989, seasonal 12-h mean ozone partial pressures in the $\mathrm{C}$ air were $75 \%$ of that in A, whereas in T, it was $190 \%$ that in A (Fig. 1). Ozone partial pressures in A averaged $93 \%$ of those in $\mathrm{N}$ in 1989. In 1990, seasonal 12-h mean ozone partial pressures in $\mathrm{C}$ were $78 \%$ of those in $\mathrm{A}$, whereas those in $\mathrm{T}$ were $180 \%$ of those in A (Fig. 1). Ozone partial pressures in A were identical to those in $\mathrm{N}$ in 1990.

\section{Gas exchange}

Within 3 (1990) or 4 (1989) months after treatments were initiated, leaf NAR of 'Casselman' plum was reduced in A and $\mathrm{T}$ when compared to those in $\mathrm{C}$ air (Fig. 2). Further reductions in 'Casselman' plum leaf Pn in the A and T chambers occurred on the remaining measurement dates in both years. There was no difference in 'Casselman' plum leaf Pn between the A and $\mathrm{N}$ plots. Stomata1 conductances of 'Casselman' plum leaves responded similarly to changing atmospheric ozone partial pressure as the leaf assimilation response (data not shown).

\section{Tree growth}

Trunk cross-sectional area growth of 'Casselman' plum was reduced in the $\mathrm{T}$ plots compared to those in the $\mathrm{C}$ plots in both years (Fig. 3, Table 1). Trunk cross-sectional area growth in A was reduced compared to that for C in 1990. Cross-sectional area growth of trees in $\mathrm{N}$ plots was less than that in A plots in 1989 and 1990.

Dormant-pruning weights on 7 Feb. 1989, 11 Jan. 1990, and 10 Jan. 1991 were similar in all the chambers (Fig. 4, Table 1). However, pruning weights for the $\mathrm{N}$ trees were less than those of trees in A plots on the dates noted. Nitrogen concentrations (percent dry weight) of the dormant prunings were $0.4 \%$,

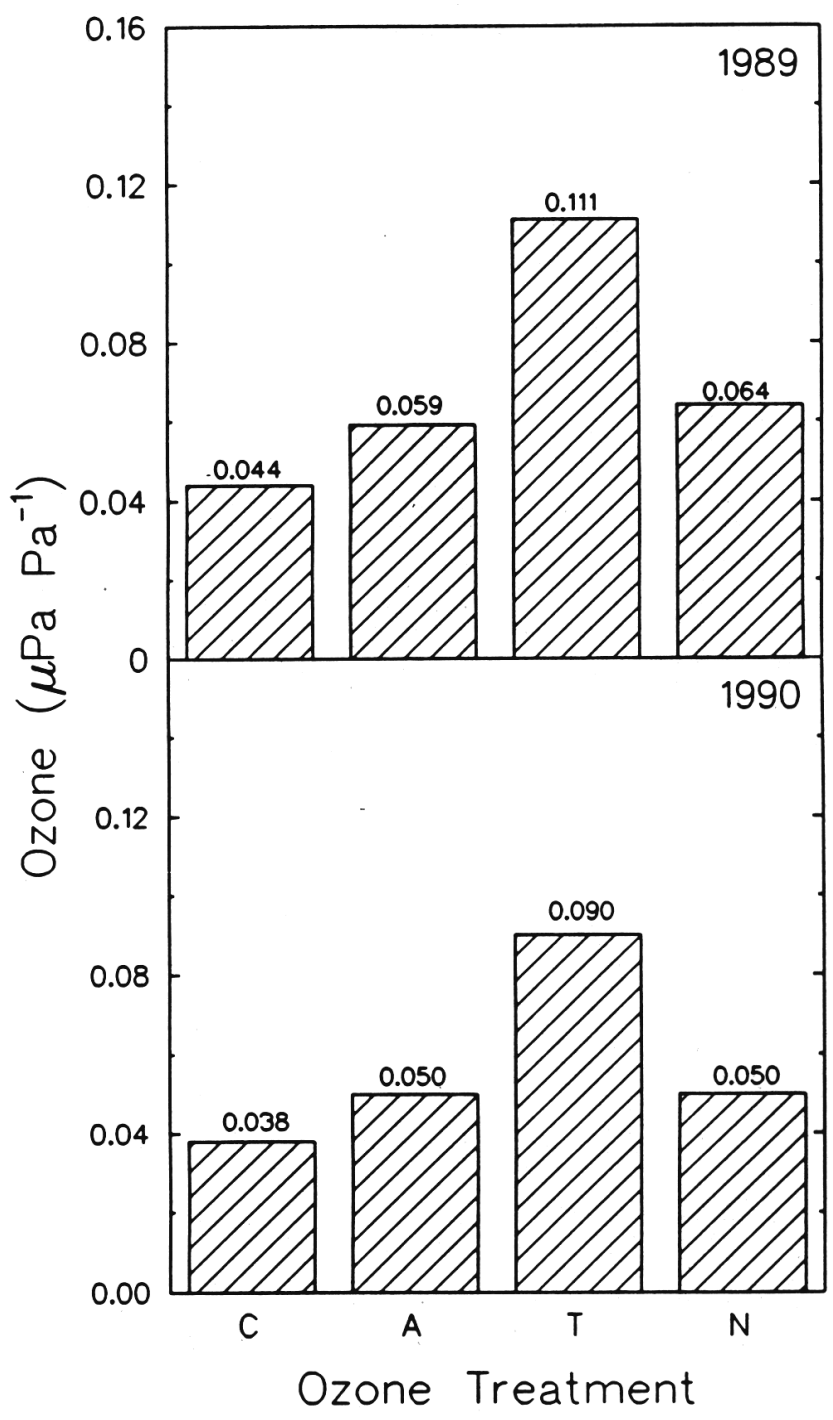

Fig. 1. Treatment 12-h (0800-2000 HR PDT) mean ozone partial pressures for the experimental period 8 May-15 Nov. 1989 and 9 Apr.-9 Nov. 1990.

$0.3 \%, 0.3 \%$, and $0.3 \%$ on $11 \mathrm{Jan} .1990$ in the C, A, T, and $\mathrm{N}$ plots, respectively, and $0.2 \%$ for all treatments on 10 Jan. 1991.

\section{Foliar injury}

Visible injury, in the form of chlorotic spots and yellow flecking on the leaf surface of older foliage, was observed on 'Casselman' plum trees in $\mathrm{T} \approx 2$ months following treatment initiation in both years. As the season progressed, foliar ozone injury increased and some leaf abscission of injured foliage occurred. No foliar ozone injury was noted in the $\mathrm{C}$, A, or $\mathrm{N}$ plots. By Nov. 1989 and 1990, >90\% of the total foliage (calculated on 15 Dec. 1989 and 30 Nov. 1990) remained on the trees in C and A plots, while $<60 \%$ remained on the trees in T plots (Fig. 5 , Table 1). Following an application of $36 \%$ zinc sulfate (16.8 $\mathrm{kg} \cdot \mathrm{ha}^{-1}$ ) on 20 Nov. 1989 and 14 Nov. 1990, most of the remaining foliage on trees in all the treatments abscised. Final cumulative foliage dry weight in $\mathrm{T}$ was less than that in $\mathrm{C}$ in 1989, but ozone did not affect final leaf dry weight in 1990 (Fig. 6, Table 1).

Seasonal average leaf nitrogen concentration (percent dry 


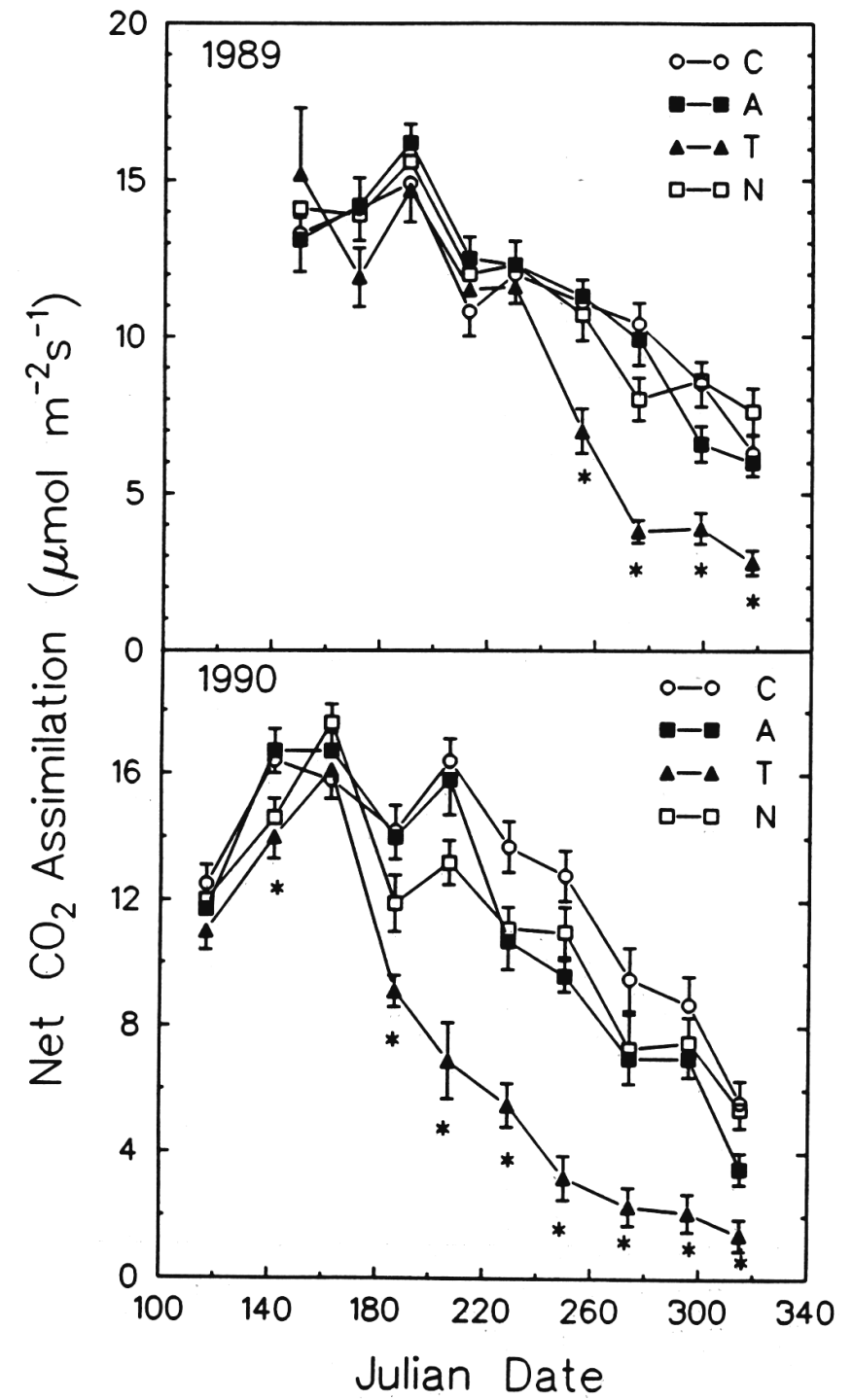

Fig. 2. Leaf Pn (measured at 3-week intervals) of 'Casselman' plum trees exposed to various atmospheric ozone partial pressures in 1989 and 1990. Vertical bars represent \pm 1 SE. Asterisks $(*)$ represent dates on which there was a significant linear treatment effect $(\alpha<$ 0.05). $\mathrm{n}=20$.

weight) of 'Casselman' plum leaf samples removed from the tree on each photosynthetic measurement date in 1989 was less in trees from $\mathrm{T}$ than from $\mathrm{C}$ (Fig. 7, Table 1). There was no difference in nitrogen concentration of attached 'Casselman' plum leaves from A and N plots in 1989 or 1990.

Leaf nitrogen concentrations of abscised leaves in the $\mathrm{C}$ and A chambers were $\approx 75 \%$ of that of the attached foliage in 1989 and 1990 (Fig. 7, Table 1). Leaf nitrogen concentration of abscised foliage from trees in $\mathrm{T}$ chambers was the same as that of the attached foliage in this treatment in 1989 , but was $-75 \%$ of the nitrogen concentration found in the attached foliage in 1990.

\section{Fruit yield}

Fruit count per tree at harvest in 1990 was reduced in the A and $\mathrm{T}$ chambers compared to $\mathrm{C}$ (Fig. 8, Table 1). Fruit count was similar for trees in $\mathrm{N}$ and A plots. Percent size distribution in each size class was unaffected by the treatments (data not

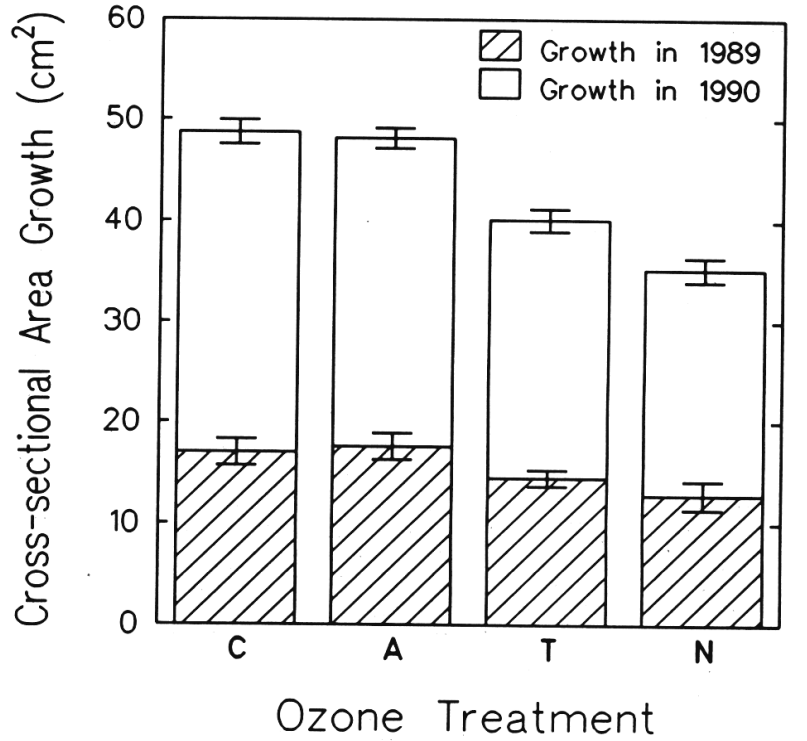

Fig. 3. Trunk cross-sectional area growth from 1 May to 1 Dec. 1989 and 1990 of 'Casselman' plum trees exposed to various atmospheric ozone partial pressures during those two years. Vertical bars represent \pm 1 SE. Probabilities of statistically significant linear ozone treatment effects are shown in Table $1 . n=20$.

shown). There was a higher percentage of fruit in the smaller size classes outside the chambers than inside and a higher percentage of fruit in the larger size classes inside the chambers than outside (data not shown). Average fruit weight was the same in all chambers, but was reduced in $\mathrm{N}$ plots compared to A (Fig. 8, Table 1). Fruit yield per tree was reduced in the A and $\mathrm{T}$ plots compared to those in the $\mathrm{C}$ plots, and there was no significant difference in fruit yield per tree between the $\mathrm{N}$ and A plots.

\section{Discussion}

Leaf Pn of 'Casselman' plum was reduced in atmospheres containing ambient and twice ambient ozone partial pressures compared to C air in 1989 and 1990 (Fig. 2). Similar results for 1-year-old 'Casselman' plum were reported previously (Retzlaff et al., 1991). In both studies, decreases in leaf Pn were not immediately apparent and only developed after an extended exposure period. In the absence of ozone, leaf photosynthetic capacity peaks early in the season and then declines gradually until leaf abscission (Pye, 1988). This pattern was exhibited by 'Casselman' plum growing in $\mathrm{C}$ atmospheres and to a certain extent in the $\mathrm{A}$ atmosphere. Increasing the atmospheric ozone partial pressure up to two times the ambient level resulted in a more rapid decline in leaf Pn, especially in 1990. Ozone has previously been found to accelerate the seasonal decline in photosynthetic capacity (Reich, 1983).

Trunk cross-sectional area growth of 'Casselman' plum was reduced by atmospheric ozone partial pressures that were nearly two times the ambient ozone partial pressure (Fig. 3). Previously, trunk cross-sectional area growth of plum was found to decrease linearly with increasing atmospheric ozone partial pressure (Retzlaff et al., 1991). Decreases in trunk growth in these two studies are apparently related to the decreases in photosynthesis and loss of photosynthetic leaf area of these trees. The additional growth of the plum trees in the "clean air" of the $\mathrm{C}$ plots (low stress) is similar to the results found in other stress 
Table 1. Probabilities of statistically significant ozone treatment effects on trunk cross-sectional area growth (Fig. 3), dormant-pruning weights (Fig. 4), leaf weight remaining on the tree (Fig. 5), total leaf dry weight (Fig. 6), leaf $\mathrm{N}$ concentration (Fig. 7), and fruit count per tree, average fruit weight, and fruit weight per tree (Fig. 8) of 'Casselman' plum exposed to various atmospheric ozone partial pressures in 1989 and 1990.

\begin{tabular}{|c|c|c|c|c|c|c|c|c|c|c|c|c|c|c|c|c|}
\hline & \multirow{2}{*}{\multicolumn{2}{|c|}{$\begin{array}{c}\text { Trunk } \\
\text { cross } \\
\text { sectional } \\
\text { area growth }\end{array}$}} & \multicolumn{3}{|c|}{ Dormant-pruning wt } & \multicolumn{2}{|c|}{$\begin{array}{l}\text { Leaf wt } \\
\text { remaining } \\
\text { on tree }\end{array}$} & \multicolumn{2}{|c|}{$\begin{array}{c}\text { Total leaf } \\
\text { dry wt }\end{array}$} & \multicolumn{4}{|c|}{ Nitrogen concn } & \multicolumn{3}{|c|}{ Fruit } \\
\hline & & & \multirow{2}{*}{$\begin{array}{c}7 \text { Feb. } \\
1989\end{array}$} & \multirow{2}{*}{$\begin{array}{c}11 \text { Jan. } \\
1990\end{array}$} & \multirow{2}{*}{$\begin{array}{c}10 \mathrm{Jan} . \\
1991 \\
\end{array}$} & \multirow{2}{*}{$\begin{array}{c}3 \text { Nov. } \\
1989 \\
\end{array}$} & \multirow{2}{*}{$\begin{array}{c}31 \text { Oct. } \\
1990\end{array}$} & \multirow{2}{*}{$\begin{array}{c}15 \text { Dec. } \\
1989\end{array}$} & \multirow{2}{*}{$\begin{array}{c}30 \text { Nov. } \\
1990\end{array}$} & \multicolumn{2}{|c|}{ Attached } & \multicolumn{2}{|c|}{ Abscised } & \multirow{2}{*}{$\begin{array}{c}\text { No./ } \\
\text { tree }\end{array}$} & \multirow{2}{*}{$\begin{array}{c}\text { Avg } \\
\text { wt }\end{array}$} & \multirow{2}{*}{$\begin{array}{l}\text { Wt/ } \\
\text { tree }\end{array}$} \\
\hline & 1989 & 1990 & & & & & & & & 1989 & 1990 & 1989 & 1990 & & & \\
\hline Lim & $*$ & $*$ & NS & NS & NS & $*$ & $*$ & $*$ & NS & $*$ & NS & $*$ & NS & $*$ & NS & $*$ \\
\hline$A v$ & * & * & NS & * & $*$ & $--{ }^{x}$ & --- & --- & --- & NS & NS & --- & -- & NS & & NS \\
\hline
\end{tabular}

${ }^{2}$ A significant linear treatment effect $(*)$ indicates that a decline in response associated with a linear increase in ozone partial pressure is significant at $P=0.05$.

${ }^{\mathrm{y}}$ A significant treatment effect $(*)$ indicates that each mean from the $\mathrm{A}$ and $\mathrm{N}$ plots is different at $P=0.05$.

${ }^{x}$ Foliage was not collected on the ground below the $\mathrm{N}$ trees, so no comparison with the A treatment could be made.

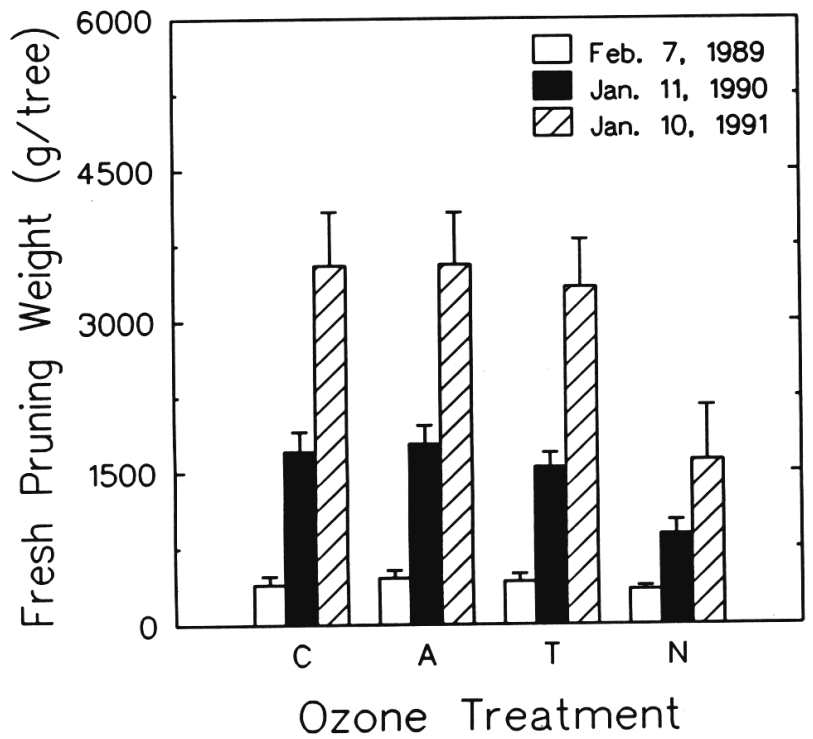

Fig. 4. Dormant fresh pruning weights on three dates for 'Casselman' plum trees exposed to various atmospheric ozone partial pressures in 1989 and 1990. Vertical bars represent \pm SE. Probabilities of statistically significant linear ozone treatment effects are shown in Table $1 . \mathrm{n}=20$.

studies. Apple trees grown in a weed-free orchard plot had a larger stem diameter and produced a more extensive branching system than trees growing with weed competition (Stinchcombe and Stott, 1983).

Other measures of growth on young 'Casselman' plum trees were affected less by increased atmospheric ozone partial pressures. Dormant-pruning weights were unaffected by ozone treatment after two seasons, illustrating the lack of a shoot response by 'Casselman' plum to changes in atmospheric ozone partial pressure (Fig. 4). Retzlaff et al. (1991) reported that shoot length, leaf count, and the number of lateral branches of 'Casselman' plum trees were unaffected by increased atmospheric ozone partial pressure. Ozone apparently alters height growth differently than diameter for plum, as has been reported previously for other trees (Pye, 1988). This may be explained, because, in fruit trees, the bulk of height growth occurs early in the growing season before the treatments affect photosynthesis, whereas diameter growth continues throughout the entire growing season (DeJong et al., 1987).

Foliar injury on 'Casselman' plum that occurred in the T plots

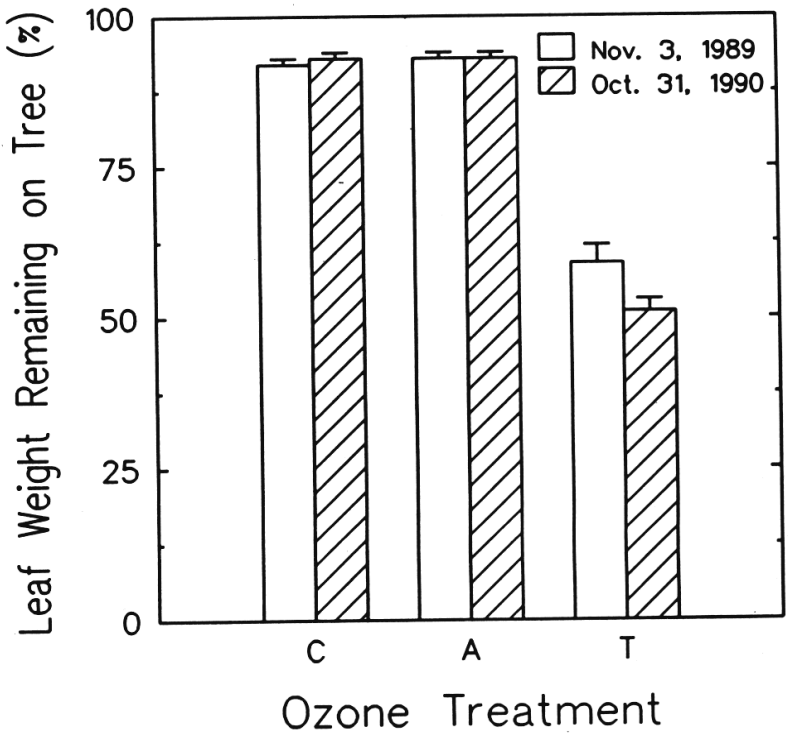

Fig. 5. Percentage of leaf dry weight remaining on two dates for 'Casselman' plum trees exposed to various atmospheric ozone partial pressures in 1989 and 1990. Vertical bars represent \pm 1 SE. Probabilities of statistically significant linear ozone treatment effects are shown in Table $1 . \mathrm{n}=5$.

was similar to that reported previously for other tree species (Chappelka et al., 1988; Keane and Manning, 1988; Retzlaff et al., 1991, 1992; Scherzer and McClenahen, 1989). Typically, this visible ozone injury is often limited to small single groups of epidermal and palisade cells resulting in flecks and stipples (Prinz, 1988). Of greater concern is the premature leaf fall observed for trees in $\mathrm{T}$ in the present study. Foliar leaf symptoms are often followed by leaf abscission (Keller, 1988; Lehnherr et al., 1987; Prinz, 1988; Reich and Amundson, 1985; Retzlaff et al., 1992). Early leaf fall in 'Casselman' plum results in a loss of photosynthetic leaf surface area that could potentially impact future growth and productivity. During the 1989 and 1990 growing seasons, 'Casselman' plum trees in the T plots lost $>40 \%$ of their foliage prematurely (Fig. 5).

Leaf senescence involves the recovery of mineral nutrients by the permanent structures of perennial plants (Grigal et al., 1976; Oland, 1963; Sacher, 1973). If ozone causes premature leaf senescence, followed by abscission (as opposed to just premature leaf abscission), then the concentrations of mineral nutrients, such as nitrogen, in leaves that have abscised should be 


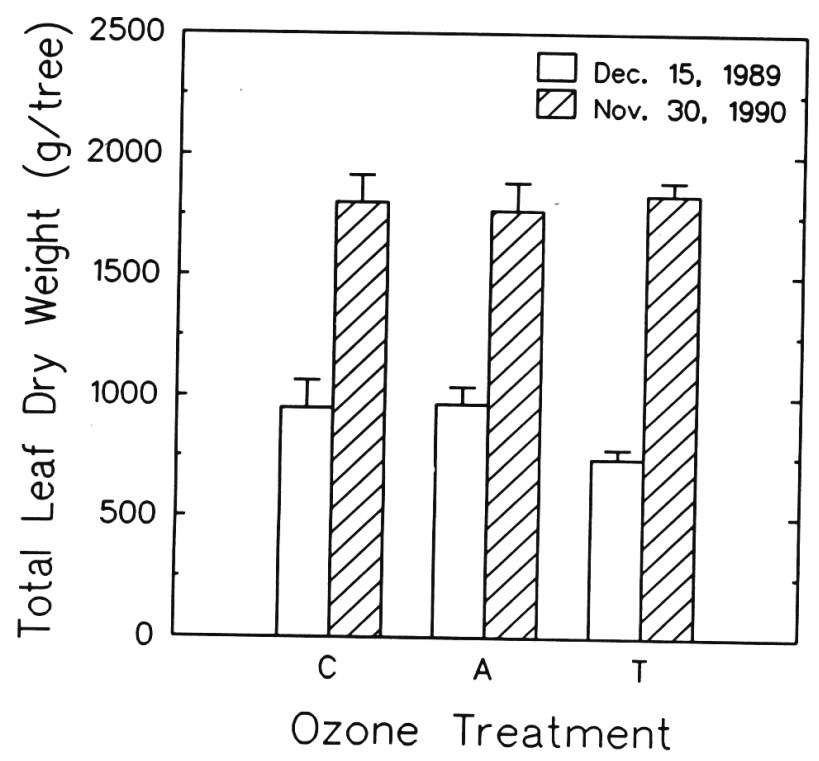

Fig. 6. Total leaf dry weight on two dates for 'Casselman' plum trees exposed to various atmospheric ozone partial pressures in 1989 and 1990. Vertical bars represent \pm 1 SE. Probabilities of statistically significant linear ozone treatment effects are shown in Table $1 . \mathrm{n}=$ 5

similar to leaves that have not been exposed to elevated ozone but have aged naturally. Foliar nitrogen concentrations of fallen 'Casselman' plum leaves were similar regardless of ozone treatment (Fig. 7). Similar results were obtained with five almond cultivars exposed to increased atmospheric ozone partial pressures for one growing season (Retzlaff et al., 1992). These data support the contention that increased atmospheric ozone causes premature leaf senescence. Further, nitrogen concentrations of the 'Casselman' plum stem prunings were unchanged by ozone treatment, indicating that chronic ozone stress did not interfere with the accumulation of nitrogen in next year's fruiting wood.

Yield data for the first bearing year (1990) indicate that increased atmospheric ozone partial pressures reduced 'Casselman' plum yield (Fig. 8). The only other report of reduced yield as a result of chronic ozone stress in fruit trees is with citrus (Olszyk et al., 1990). Yields of 'Valencia' orange trees were $11 \%$ lower at $0.040 \mu \mathrm{Pa} \cdot \mathrm{Pa}^{-1}$ (ambient) and $31 \%$ lower at 0.075 $\mu \mathrm{Pa} \cdot \mathrm{Pa}^{-1}$ (1.8 times ambient) ozone compared to $0.020 \mu \mathrm{Pa} \cdot \mathrm{Pa}^{-1}$ ozone (charcoal-filtered). The number of oranges per tree and individual weight per orange was reduced in the 1.8-times ambient ozone partial pressures, indicating that elevated atmospheric ozone was somehow affecting orange set as well as carbon allocated to the orange fruit. This result differs somewhat from the response of 'Casselman' plum. Yield reductions of $28 \%$ in $\mathrm{A}$ and $38 \%$ in the 1.8-times, ambient ozone treatments compared to yields in $\mathrm{C}$ were only the result of a reduced fruit count per tree and not plum size, since the average weight per plum was the same in all chamber ozone treatments.

Ozone-induced reductions in the number of plum fruit per tree could be the result of several factors. Ozone-induced reductions in photosynthesis are often related to declines in yield (Reich and Amundson, 1985). Stinchcombe and Scott (1983) have shown that apple trees grown in plots with reduced competition stress (weed free) had a significantly higher fruit set than those in plots with weed competition. The fruit set response was attributed to the fact that trees in the competing plots stopped growing sooner in August than those in the weed-free plots.

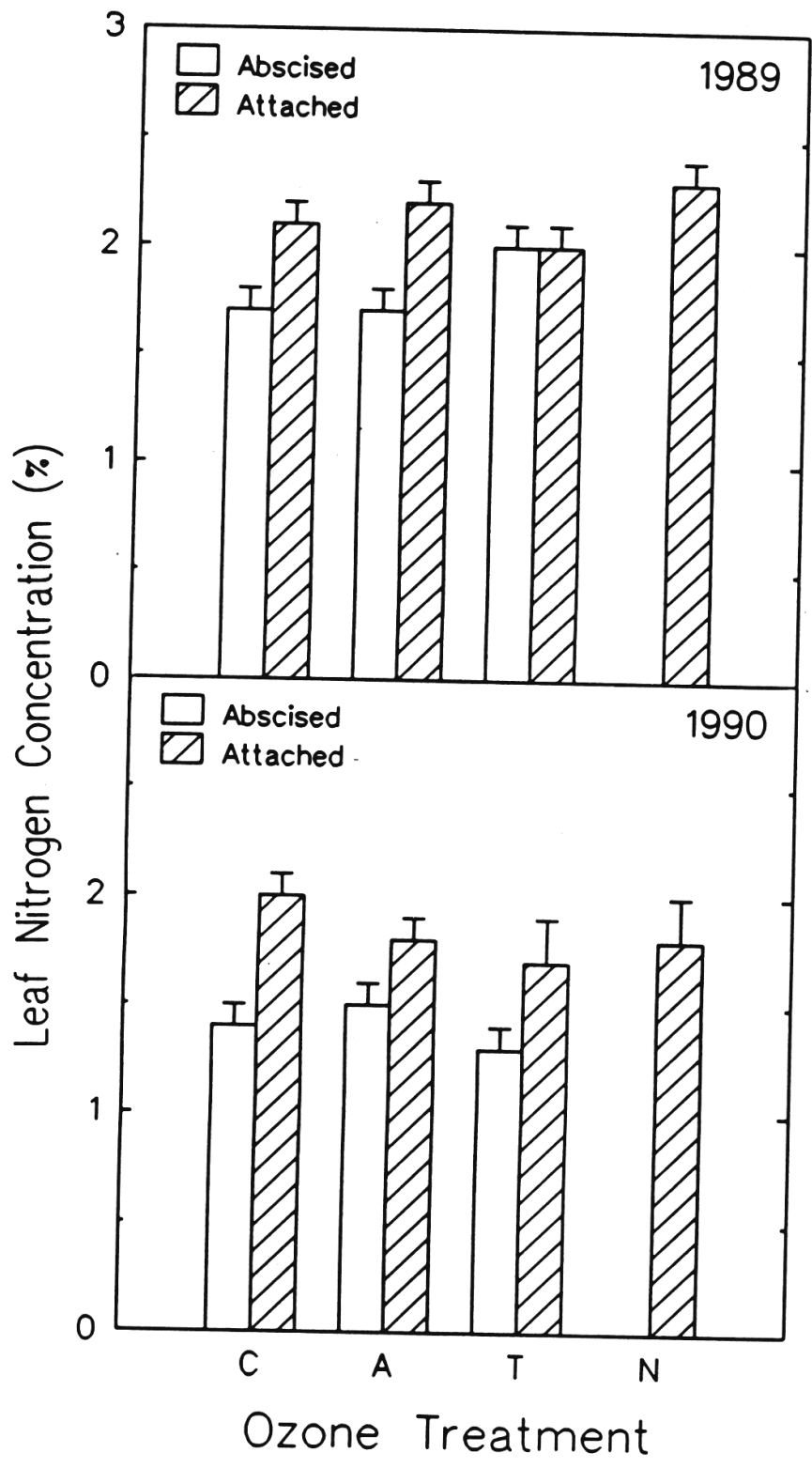

Fig. 7. Leaf nitrogen concentration (percent dry weight) of attached and abscised foliage from 'Casselman' plum trees exposed to various atmospheric ozone partial pressures in 1989 and 1990. Vertical bars represent \pm 1 SE. Probabilities of statistically significant linear ozone treatment effects are shown in Table 1. $\mathrm{n}=40$ (attached 1989); $\mathrm{n}$ $=20$ (abscised 1989); $\mathrm{n}=15$ (attached 1990); $\mathrm{n}=20$ (abscised 1990).

Since fruit bud formation is more active later in the season, this extension of the growing period would be expected to increase the formation of fruit buds and, thus, yields (Abbott, 1977). A similar response could be hypothesized for fruit trees under chronic ozone stress.

Late-season declines in photosynthesis and loss of photosynthetic leaf surface area of 'Casselman' plum trees in increased atmospheric ozone partial pressures could result in a lack of sufficient carbohydrates for fruit bud formation during the latter part of the growing season. In addition, 'Casselman' plum trees growing in the 1.8-times ambient ozone atmospheres had three periods of light bloom during Aug. and Sept. 1990. Fall bloom in stone fruits is commonly associated with premature leaf fall 


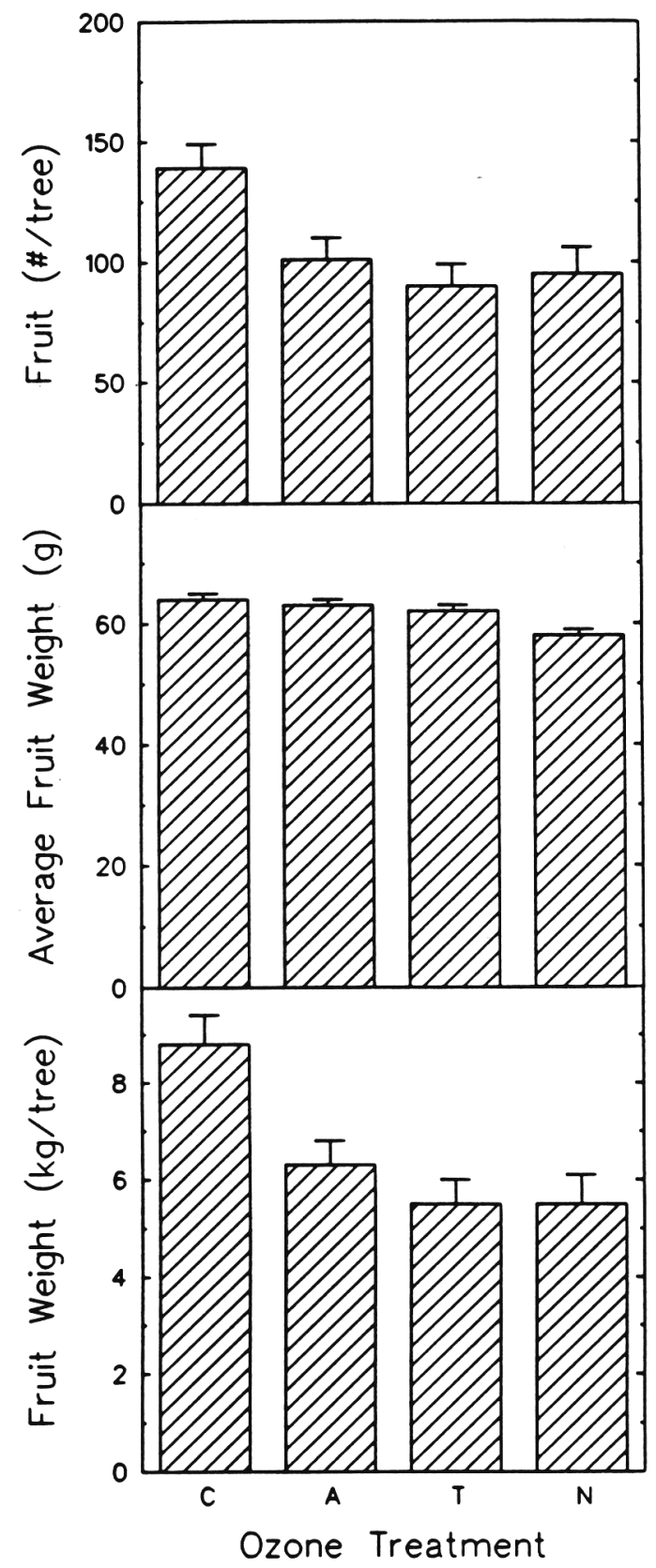

Fig. 8. Number of fruit per tree, average fruit weight, and fruit weight per tree in 1990 of 'Casselman' plum trees exposed to various atmospheric ozone partial pressures in 1989 and 1990. Vertical bars represent \pm 1 SE. Probabilities of statistically significant linear ozone treatment effects are shown in Table 1. $\mathrm{n}=20$.

induced by environmental stress, such as water deficits or salinity stress. In this study, late-season bloom was attributed to chronic ozone stress and could be a factor in the loss of yield during following growing seasons. It is not clear whether there is a direct effect of ozone fumigation on the flower buds once they are formed on the tree branch or an indirect one due to lack of carbohydrates. Counts of flower buds and fruit set are needed to quantify this reduction in plum fruit count induced by ozone exposure.

Comparison of 'Casselman' plum trees inside the A chambers vs. those outside in the ambient ozone (treatment $\mathrm{N}$ ) indicates little difference in leaf Pn and growth response (Figs. 2-4). In contrast, rates of photosynthesis in cotton (Gossypium hirsutum L.) grown in $\mathrm{N}\left(0.077 \mu \mathrm{Pa} \cdot \mathrm{Pa}^{-1}\right.$ ozone $)$ plots were less than those in chambers with ambient air $\left(0.074 \mu \mathrm{Pa} \cdot \mathrm{Pa}^{-1}\right.$ ozone $)$ (Temple et al., 1988). The most commonly observed chamber effect is that plants grown inside them tend to be taller than plants grown outside (Heagle, 1989). Pruning weight data from the 'Casselman' plum trees support this observation, with trees in the A plots having more shoot growth than trees in the $\mathrm{N}$ plots. Further, cross-sectional area growth of 'Casselman' plum trees in the A plots exceeded that of trees in the $\mathrm{N}$ plots. One explanation of this effect could be that the outside trees were smaller $\left(11.1-\mathrm{cm}^{2}\right.$ cross-sectional area in the $\mathrm{N}$ plots vs. 12.3 $\mathrm{cm}^{2}$ in the A chambers) when the study was initiated. Since cross-sectional area increases geometrically, larger trees would be expected to get larger even if growing at the same rate as smaller trees. Further, some of the trees in the $\mathrm{N}$ plots were transplanted in Dec. 1988 to replace dead trees and have not caught up with the remainder of the orchard during establishment.

One other way to measure the effects of open-top chambers is to compare the yield of plants inside the chambers with yield of plants grown without chambers (Heagle, 1989). Yield of 'Casselman' plum trees grown outside the chamber in ambient partial pressures of ozone was the same as those of trees grown inside chambers with ambient partial pressures of atmospheric ozone (Fig. 8). The atmospheric ozone partial pressure was reduced by $\approx 7 \%$ in the A chambers compared to the $\mathrm{N}$ plots in the present study, but there were no leaf photosynthesis or yield differences between the two plots. The open-top chambers apparently had little effect on the overall physiology and yield of 'Casselman' plum trees, and results from this study could be extrapolated to trees of the same age growing under true orchard conditions.

Exposure of 'Casselman' plum trees to increased atmospheric ozone partial pressure over two growing seasons reduced leaf $\mathrm{Pn}$, induced premature leaf fall, and decreased cross-sectional area growth of the trunk. More importantly, even though the trees in this study were only exposed to controlled ozone treatments for 2 years following the first year of initial orchard establishment, increased ozone partial pressure exposure significantly reduced yield the first bearing year. Results from a study on 1-year-old 'Casselman' plum trees (Retzlaff et al., 1991) indicate that if the ozone response is cumulative, then the ozone effect would have been greater in the present study had the plum trees been exposed to increased atmospheric ozone partial pressures during the first year. Clearly, chronic ozone stress has a detrimental effect on plum tree growth and yield during the orchard establishment period. The effects of ozone air pollution on mature orchard growth and yields and the components of yield that are affected by ozone stress remain to be determined.

\section{Literature Cited}

Abbott, D.L. 1977. Fruit bud formation in Cox's Orange Pippin. Rpt. Long Ashton Res. Sta. 1976. p. 167-176.

Adaros, G.H., J. Weigal, and H.J. Jager. 1990. Effects of incremental ozone concentrations on the yield of bush beans (Phaseolus vulgaris var. nanus [L.] Aschers.) Gartenbauwissenschaft 4:162-167.

Brewer, R.F. and R. Ashcroft. 1983. The effects of ambient air pollution on Thompson Seedless grapes. Final Report on Air Resources Board Contract Al-132-33. The effect of present and potential air pollution on important San Joaquin Valley crops: Grapes.

Cabrera, H.S., S.V. Dawson, and C. Stromberg. 1988. A California air standard to protect vegetation from ozone. Environ. Pollution 53:397-408. 
Chappelka, A.H., B.I. Chevone, and T.T. Burk. 1988. Growth response of green and white ash seedlings to ozone, sulfur dioxide, and simulated acid rain. For. Sci. 34:1016-1029.

DeJong, T.M., J.F. Doyle, and K.R. Day. 1987. Seasonal patterns of reproductive and vegetative sink activity in early and late maturing peach (Prunus persica) cultivars. Physiol. Plant. 71:63-69.

Grigal, D.F., L.F. Ohmann, and R.B. Brander. 1976. Seasonal dynamics of tall shrubs in northeastern Minnesota: Biomass and nutrient element changes. For. Sci. 22:195-208.

Heagle, A.S. 1989. Ozone and crop yield. Annu. Rev. Phytopathol. 27:397-423.

Keane, K.D. and W.J. Manning. 1988. Effects of ozone and simulated acid rain on birch seedling growth and formation of ectomycorrhizae. Environ. Pollution 52:55-65.

Keller, T. 1988. Growth and premature leaf fall in American aspen as bioindicators for ozone. Environ. Pollution 52:183-192.

LaRue, J.H. and R.S. Johnson. 1989. Peaches, plums and nectarines: Growing and handling for fresh market. Univ. of California Coop. Ext. Publ. 3331.

Lehnherr, B., F. Machler, A. Granjean, and J. Fuhrer. 1987. The regulation of photosynthesis in leaves of field-grown spring wheat (Triticum aestivum L. cv. Albis) at different levels of ozone in ambient air. J. Plant Physiol. 88:1115-1119.

Mebrahtu, T., W. Mersie, and M. Rangappa. 1991. Path coefficient analysis of ozone effects on seed yield and seed yield components of bean (Phaseolus vulgaris L.) J. Hort. Sci. 66:59-66.

Oland, K. 1963. Changes in the content of dry matter and major nutrient elements of apple foliage during senescence and abscission. Physiol. Plant. 28:682-694.

Olszyk, D.M., G. Kats, C.L. Morrison, P.J. Dawson, I. Gocka, J. Wolf, and C.R. Thompson. 1990. Valencia orange fruit yield with ambient oxidant or sulfur dioxide exposures. J. Amer. Soc. Hort. Sci. 115:878-883

Prinz, B. 1988. Ozone effects on vegetation, p. 161-184. In: I.S.A.
Isaksen (ed.). Tropospheric ozone. D. Reidel Publishing Co., Germany.

Pye, J.M. 1988. Impact of ozone on the growth and yield of trees: A review. J. Environ. Qual. 17:347-360.

Reich, P.B. 1983. Effects of low concentrations of ozone on net photosynthesis, dark respiration, and chlorophyll contents in aging hybrid poplar leaves. Plant Physiol. 73:291-296.

Reich, P.B. and R.G. Amundson. 1985. Ambient levels of ozone reduce net photosynthesis in tree and crop species. Science 230:566570.

Retzlaff, W.A., T.M. DeJong, and L.E. Williams. 1992. Photosynthesis and growth response of almond to increased atmospheric ozone partial pressures. J. Environ. Qual. 21:208-216.

Retzlaff, W.A., L.E. Williams, and T.M. DeJong. 1991. The effect of different atmospheric ozone partial pressures on photosynthesis and growth of nine fruit and nut tree species. Tree Physiol. 8:93105.

Sacher, J.A. 1973. Senescence and post-harvest physiology. Annu. Rev. Plant Physiol. 24:197-224.

SAS Institute. 1985. SAS user's guide: Basics. 1985 ed. SAS Institute, Cary, N.C.

Scherzer, A.M. and J.R. McClenahen. 1989. Effects of ozone or sulfur dioxide on pitch pine seedlings. J. Environ. Qual. 18:57-61.

Stinchcombe, G.R. and K.G. Stott. 1983. A comparison of herbicidecontrolled orchard ground cover management systems on the vigor and yield of apples. J. Hort. Sci. 58:477-489.

Takemoto, B.K., A. Bytnerowicz, and D.M. Olszyk. 1988. Depression of photosynthesis, growth, and yield in field-grown green pepper (Capsicum annum L.) exposed to acidic fog and ambient ozone. Plant Physiol. 88:477-482.

Temple, P.J., R.S. Kupper, R.W. Lennox, and K. Rohr. 1988. Physiological and growth responses of differentially irrigated cotton to ozone. Environ. Pollution 53:255-263. 